\title{
Age-related changes in expression in renal AQPs in response to congenital, partial, unilateral ureteral obstruction in rats
}

\author{
Guixian Wang • Weitang Yuan • Tae-Hwan Kwon - Zhenzhen Li • Jianguo Wen • \\ Sukru Oguzkan Topcu • Jens Christian Djurhuus • Søren Nielsen • Jørgen Frøkiær
}

Received: 24 September 2010 /Revised: 6 March 2011 / Accepted: 9 March 2011 /Published online: 25 October 2011

(C) The Author(s) 2011. This article is published with open access at Springerlink.com

\begin{abstract}
Previously we demonstrated that neonatally induced partial unilateral ureteral obstruction (PUUO) in rats is associated with changes in the abundance of renal acid-base transporters that were paralleled by reduction in renal functions dependent on the severity and duration of obstruction. The aim of the present study was to identify whether changes in renal aquaporin abundance are agedependent. Semiquantitative immunoblotting and immuno-
\end{abstract}

G. Wang $\cdot$ W. Yuan $\cdot$ Z. Li $\cdot$ J. Wen

Department of Colorectoanal Surgery and Institute of Clinical Medicine, The First Affiliated Hospital, Zhengzhou University, Zhengzhou, China

G. Wang · T.-H. Kwon • Z. Li • S. O. Topcu $\cdot$ S. Nielsen $•$

J. Frøkiær ( $\bowtie)$

The Water and Salt Research Center,

Aarhus University Hospital-Skejby,

8200 Aarhus, Denmark

e-mail: jf@ki.au.dk

G. Wang $\cdot$ Z. Li $\cdot$ S. O. Topcu $\cdot$ J. C. Djurhuus $\cdot$ J. Frøkiær Institute of Clinical Medicine, University of Aarhus,

Aarhus, Denmark

S. Nielsen

Institute of Anatomy, University of Aarhus,

Aarhus, Denmark

T.-H. Kwon

Department of Biochemistry and Cell Biology,

School of Medicine, Kyungpook National University,

Taegu 700-422, Korea

J. Frøkiær

Department of Clinical Physiology,

Aarhus University Hospital-Skejby,

Aarhus N, Denmark histochemistry were used to examine the changes in abundance of AQP1, AQP2, p-S256AQP2 (AQP2 phosphorylated at consensus site $\mathrm{Ser}^{256}$ ) and AQP3 in the kidneys of rats with neonatally induced PUUO within the first $48 \mathrm{~h}$ of life, and then monitored for 7 or 14 weeks. Protein abundance of AQP2 and AQP3 increased in both obstructed and non-obstructed kidneys 7 weeks after induction of neonatal PUUO (PUUO-7W). In contrast, AQP1 and AQP2 protein abundance in the obstructed kidney were reduced after 14 weeks of PUUO (PUUO$14 \mathrm{~W})$. Importantly, pS256-AQP2 protein abundance was reduced in obstructed kidneys of both PUUO-7W and PUUO-14W. Immunohistochemistry confirmed the persistent pS256-AQP2 downregulation in both PUUO-7W and PUUO-14W rats. The study shows that the protein abundance of AQP1, AQP2, and AQP3 in the obstructed kidney is increased in PUUO-7W, which may be a compensatory phenomenon and reduced in PUUO-14W rats suggesting a time-/age-dependent dysregulation in response to PUUO. pS256-AQP2 protein abundance is reduced consistent with obstruction-induced direct effects in the apical part of the collecting duct principal cells in response to PUUO.

Keywords Partial ureteral obstruction - AQP1 - AQP2 . pS256-AQP2 - AQP3

\section{Introduction}

Congenital urinary tract obstruction is a frequent manifestation in neonates with malformation of the urinary tract 
and obstruction is characterized by profound impairment of kidney functions including reductions in both glomerular filtration rate (GFR) and tubular handling of water and solutes[1]. However, the management of antenatally detected hydronephrosis is still debated [2, 3]. Early surgical intervention is controversial owing to limited understanding of the natural history of congenital hydronephrosis. To understand the development and the pathophysiological mechanisms involved in congenital obstructive uropathy we have developed a rat model with neonatal partial unilateral ureteral obstruction (PUUO) [4]. Since more than $90 \%$ of nephrogenesis in the rat takes place postnatally during the first 10 days of life, this is an attractive experimental model for studying congenital obstructive nephropathy, which may resemble the midand last trimester in the human foetus [5].

Characteristically, a very important sign of urinary tract obstruction is impairment of urinary concentrating capacity [6], which depends on the discrete segmental distribution of transport properties along the renal tubule: the hypertonic medullary interstitium, which is generated by active $\mathrm{NaCl}$ reabsorption in water-impermeable nephron segments, and the high water permeability (constitutive or vasopressinregulated) in other renal tubular segments for osmotic equilibration, which chiefly depends on aquaporins (AQPs) [7]. Thus, defects in any of these mechanisms would be predicted to be associated with urinary-concentrating defects.

The AQPs are a family of membrane proteins that function as water channels[8]. AQP1 is highly abundant in the proximal tubule and descending thin limb [9], whereas AQP2 is the apical water channel of the principal cells and the chief target for regulation of collecting duct water permeability by vasopressin[10, 11]. Water transport across the basolateral plasma membrane of collecting duct principal cells is mediated by AQP3 [12] and AQP4[13]. Consistent with the roles of AQPs in renal regulation of water balance, we recently demonstrated that complete unilateral ureteral obstruction in adult rat causes severe downregulation of renal AQPs, which is associated with impaired renal water handling[14, 15]. Previous studies in our lab also demonstrated that AQP2 protein abundance in the kidney subjected to congenital partial ureter obstruction was reduced at 12 and 24 weeks of age. Consistent with this, solute-free water reabsorption was decreased, suggesting that AQP2 expression also plays a crucial role for the impairment of urine concentration during chronic partial ureter obstruction of the kidney [16].

Since the newborn rat model with PUUO is associated with the development of early progressive hydronephrosis [4], the aims of this study were therefore to investigate whether protein abundance of renal AQP1, AQP2, and $\mathrm{AQP} 3$ is time-/age-dependent in response to partial ureter obstruction.

\section{Materials and methods}

Experimental protocol

Experiments were performed using the same sample materials as from previously studied PUUO rats where expression patterns in acid-base transporters were examined [17]. Male rats (Munich-Wistar, Møllegaard Breeding Centre, Eiby, Denmark) were subjected to PUUO or sham operation within the first $48 \mathrm{~h}$ of life as described previously $[4,16,18]$. In brief, PUUO was created by a modification of Ulm and Miller's technique [19], which results in the development of hydronephrosis. This study included 41 (2-day-old) male Munich-Wistar rats, weighing 6-8 g, randomized into two groups: PUUO $(n=23)$, and SHAM operation $(n=18)$.

Newborn rats, weighing 6-8 g, are poikilothermic, and adult thermoregulatory capabilities do not develop until week 3 of life. Because of their small body mass, rapid core cooling can be achieved by surface cooling [20]. Accordingly, the newborn rat was placed on crushed ice for about $8-10 \mathrm{~min}$. When the rat was deeply asleep, it was placed at the operating table. If needed, additional crushed ice was placed around the body and neck region during the operation. Normally, placement of a newborn rat on crushed ice for $8-10 \mathrm{~min}$ is sufficient to maintain anesthesia for 30-40 min.

Partial unilateral ureteral obstruction of the left ureter was created according to a modification of the technique of Ulm and Miller[19]. The left ureter was exposed via an abdominal transperitoneal incision using a microscope with $\times 25$ magnification. The underlying psoas muscle was split longitudinally to form a groove, into which the upper two thirds of the left ureter were embedded. The muscle edges were closed by Ethilon sutures (9-0). In the SHAM group, a laparotomy was performed and the left ureter was exposed. After surgery, rats were placed in an incubator with a temperature of $28^{\circ} \mathrm{C}$ until they were awakened; then they were returned to the regular units with their mothers. The mother rats had free access to a standard rodent diet and were kept in an animal facility with a controlled room temperature of $21 \pm 2^{\circ} \mathrm{C}$ and 12:12-h dark-light cycle.

At day 21 of life, the rats were separated from their mother and divided randomly into the following protocols:

1. PUUO-7W $(n=13)$, in which the animals were subjected to PUUO and followed for 7 weeks before sacrifice. Both obstructed and contralateral nonobstructed kidneys from five PUUO-7W rats were used for immunoblotting. Immunohistochemistry were performed on five PUUO-7W rats.

2. SHAM-7W $(n=8)$. The left kidney from SHAM-7W rats $(n=5)$ was harvested and used for immunoblotting, 
and the left kidney from the remaining sham-operated rats was used for immunohistochemistry $(n=3)$.

3. PUUO-14W $(n=10)$, in which the animals were subjected to PUUO and followed for 14 weeks before sacrifice. Both obstructed and contralateral nonobstructed kidneys from six PUUO-14W rats were used for immunoblotting. The other harvested kidneys from the remaining PUUO-14W rats $(n=4)$ were used for immunohistochemistry.

4. SHAM-14W $(n=10)$. The left kidney from six SHAM$14 \mathrm{~W}$ rats was used for immunoblotting, and the left kidney from the remaining SHAM-14W $(n=4)$ was used for immunohistochemistry.

All procedures conformed with the Danish National Guidelines for care and handling of animals and to the published guidelines from the National Institutes of Health. The experimental animal protocols were approved by the board of the Institute of Clinical Medicine, Faculty of Health Sciences, Aarhus University, according to the licenses for use of experimental animals issued by the Danish Ministry of Justice.

Urine and blood sampling and analysis

Urine from the last $24 \mathrm{~h}$ was collected every morning while the rats were in metabolic cages. Urinary sodium concentration was determined by standard flame photometry (Eppendorf FCM6341). Before termination of animals, about $4 \mathrm{ml}$ of arterial blood was drawn from the abdominal aorta. Then both kidneys were quickly removed and frozen for subsequent immunoblotting. The blood was centrifuged for $15 \mathrm{~min}$ at $4,000 \mathrm{~g}$ to remove the blood cells, and subsequently the plasma was analyzed for sodium, potassium, creatinine, and urea with a Vitros 950(Johnson \& Johnson). The osmolality of plasma and urine was measured by freezing-point depression (The Advanced Osmometer, model 3900; Advanced Instruments, Norwood, MA, USA and the Osmomat 030-D; Gonotec, Berlin, Germany).

\section{Electrophoresis and immunoblotting}

Both the obstructed kidney (OBS) and contralateral nonobstructed kidney (CON) from PUUO rats, and the left kidney from SHAM rats were collected for semiquantitative immunoblotting. The sampling kidney was minced finely and homogenized in $7 \mathrm{ml}$ of ice cold dissecting buffer (0.3 M sucrose, $25 \mathrm{mM}$ imidazole, $1 \mathrm{mM}$ EDTA, $\mathrm{pH} 7.2$, and containing the following protease inhibitors: $8.5 \mu \mathrm{M}$ leupeptin, $1 \mathrm{mM}$ phenylmethyl sulfonyl fluoride), with five strokes of a motor-driven IKA homogenizer at 1,250 rpm.
This homogenate was centrifuged in a Beckman L8M centrifuge at $4,000 \mathrm{~g}$ for $15 \mathrm{~min}$ at $4{ }^{\circ} \mathrm{C}$. The supernatants were assayed for protein concentration using the BCA protein assay method. Gel samples (in Laemmli sample buffer containing $2 \% \mathrm{SDS}$ ) were made from this membrane preparation. According to the total protein concentration, the loading volumes of different samples were calculated. Samples of membrane fractions were run on 12 SDSpolyacrylamide minigels (Bio-Rad Mini Protean II). For each gel, an identical gel was run in parallel and subjected to Coomassie blue staining. The Coomassie blue stained gel was used to ascertain identical loading or to allow for potential correction for minor differences in loading after scanning and densitometry of major bands. The other gel was subjected to blotting. After transfer by electroelution to nitrocellulose membranes, blots were blocked with $5 \%$ milk in PBS-T (80 mM Na $2 \mathrm{HPO}_{4}, 20 \mathrm{mM} \mathrm{NaH} \mathrm{PO}_{4}, 100 \mathrm{mM}$ $\mathrm{NaCl}, 0.1 \%$ Tween $20, \mathrm{pH} 7.5$ ) for $1 \mathrm{~h}$ and incubated with primary antibodies overnight at $4^{\circ} \mathrm{C}$. After being washed with PBS-T, the blots were incubated with horseradish peroxidase-conjugated secondary antibody (P448, DAKO A/S, Glostrup Denmark, diluted 1:3,000) for $1 \mathrm{~h}$. After a final washing as above, antibody binding was visualized by using the enhanced chemiluminescence system (Amersham). Enhanced chemiluminescence films with bands within the linear range were scanned (Arcus II, Agfa, and Corel Photopaint software). The labeling density was corrected by densitometry of the Coomassie blue-stained gels.

\section{Immunohistochemistry}

Kidneys were fixed by retrograde perfusion via the abdominal aorta with $4 \%$ paraformaldehyde in $0.1 \mathrm{M}$ cacodylate buffer, $\mathrm{pH}$ 7.4.For immunoperoxidase microscopy, kidney blocks containing all kidney zones were dehydrated and embedded in paraffin. The paraffinembedded tissues were cut (into $2-\mu \mathrm{m}$ pieces) on a rotary microtome (Leica). The sections were deparaffinized and rehydrated. For immunoperoxidase labeling, endogenous peroxidase were blocked by $0.5 \% \quad \mathrm{H}_{2} \mathrm{O}_{2}$ in absolute methanol for $10 \mathrm{~min}$ at room temperature. To reveal antigens, sections were put in $1 \mathrm{mmol} / \mathrm{l}$ Tris solution $(\mathrm{pH}$ 9.0) supplemented with $0.5 \mathrm{mM}$ EGTA and heated using a microwave oven for $10 \mathrm{~min}$. Nonspecific binding of Ig was prevented by incubating the sections in $50 \mathrm{mM} \mathrm{NH}_{4} \mathrm{Cl}$ for $30 \mathrm{~min}$, followed by blocking in PBS supplemented with $1 \%$ BSA, $0.05 \%$ saponin, and $0.2 \%$ gelatin. Sections were incubated overnight at $4{ }^{\circ} \mathrm{C}$ with primary antibodies diluted in PBS supplemented with $0.1 \%$ BSA and $0.3 \%$ Triton X100. After being rinsed with PBS supplemented with $0.1 \%$ BSA, $0.05 \%$ saponin, and $0.2 \%$ gelatin for $3 \times 10 \mathrm{~min}$, the sections were incubated in horseradish peroxidase- 
a

PUUO-7W, AQP2

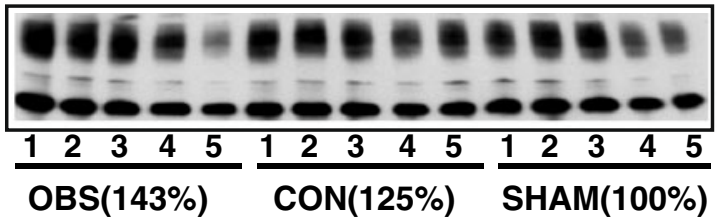

b

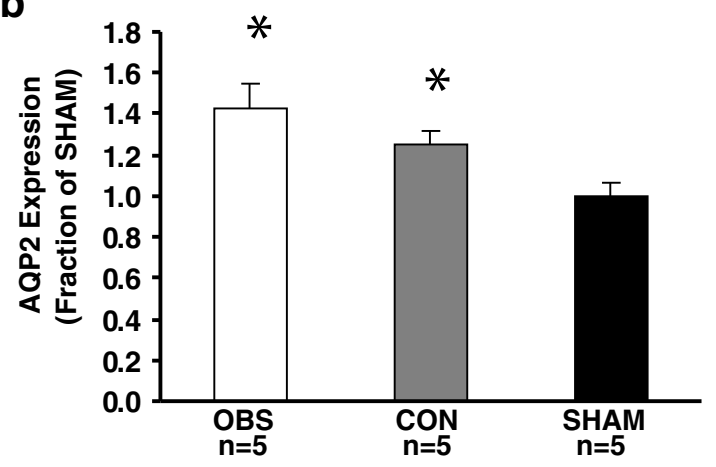

d

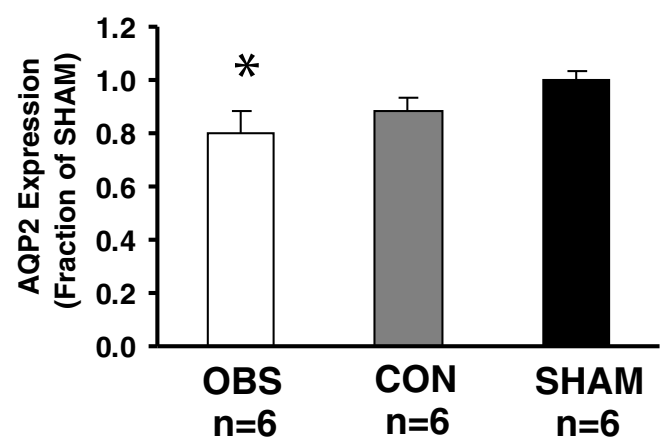

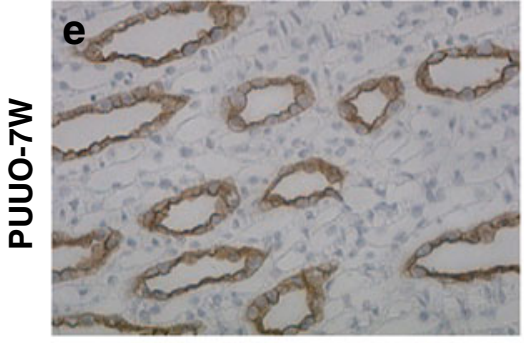

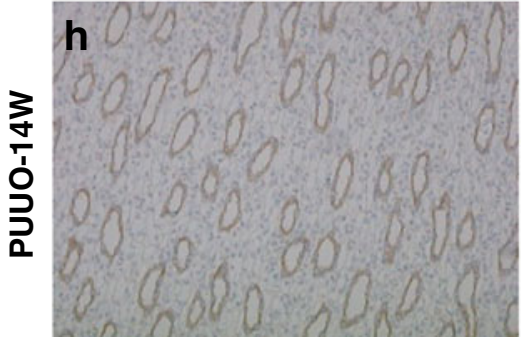

OBS
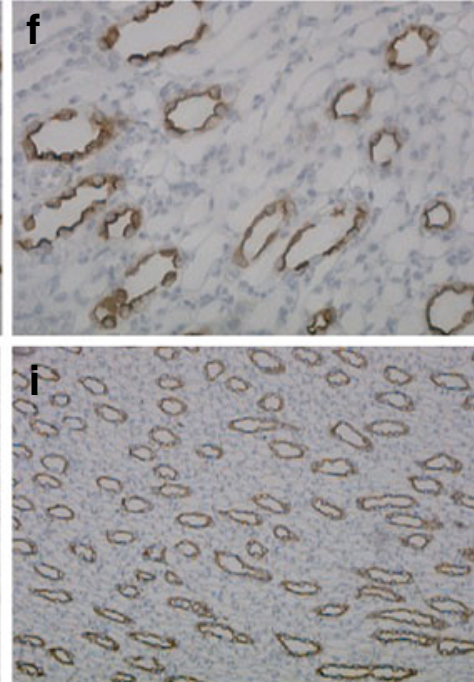

CON
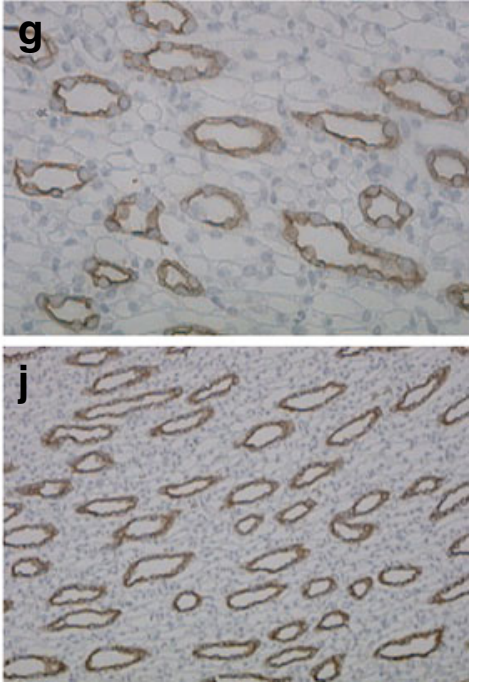

SHAM
Fig. 1 Semiquantitative immunoblotting of membrane fractions of obstructed whole kidneys $(O B S)$ and contralateral non-obstructed kidneys $(C O N)$ from (partial unilateral ureteral obstruction) PUUO$7 \mathrm{~W}$ and PUUO-14W rats, and kidneys from matched sham-operated control rats $(S H A M)$. a and c Immunoblots reacted with affinitypurified AQP2 antibody revealed 29-and 35-to 50-kDa bands. b Densitometry analysis in PUUO-7W revealed a marked increase in the abundance of AQP2 to $143 \pm 12 \%$ in OBS and $125 \pm 7 \%$ in $\mathrm{CON}$ $(P<0.05$ separately, compared with SHAM). d Densitometry analysis in PUUO-14W revealed a marked decrease in the abundance of AQP2 to $80 \pm 8 \%$ in OBS $(P<0.05$ compared with SHAM). In CON, AQP2 expression did not change compared with SHAM. Immunohistochemistry of AQP2 in the collecting ducts of OBS, CON, and SHAM from 7- and 14-week-old PUUO and SHAM rats. In PUUO-7W the immunolabeling was intense in e OBS and $\mathbf{f}$ CON compared with $\mathbf{g}$ SHAM, whereas in PUUO-14W the immunolabeling was much weaker in $\mathbf{h}$ OBS and comparable in $\mathbf{i}$ CON compared with $\mathbf{j}$ SHAM. Magnification: $\times 250$ 
conjugated secondary antibodies (P448, DAKO) diluted $1: 200$ in PBS supplemented with $0.1 \%$ BSA and $0.3 \%$ Triton X-100, followed by incubation with diaminobenzidine. The microscopy was carried out using a Leica DMRE light microscope.

Primary antibodies

For semiquantitative immunoblotting and immunohistochemistry, we used previously characterized polyclonal antibodies to several water channels, as follows:

1. AQP1 (2353 AP fr 2-5): an affinity-purified antibody to AQP1 [21].

2. AQP2 (H7661 Ap fr 3-4): an affinity-purified antibody to AQP2 [22].

3. pS256-AQP2 (KO 407 AP). An affinity-purified rabbit polyclonal antibody to $\mathrm{pS} 256-\mathrm{AQP} 2$ has previously been described [23].

4. AQP3 (1591AP): an affinity-purified polyclonal antibody to AQP3 has previously been described [21, 24].

Statistical analysis

For the densitometry of immunoblots, samples from experimental kidneys were run on each gel with corresponding sham kidneys. Renal AQP expression in the samples from the experimental animals was calculated as a fraction of the mean sham control value for that gel. Parallel Commassie-stained gels were subjected to densitometry and used for correction of potential minor differences in loading. Values are presented as means $\pm \mathrm{SE}$. Comparisons between groups were made by unpaired $t$ test. One-way ANOVA analysis was used for comparison in more than two groups. $P$ values $<0.05$ were considered statistically significant.

\section{Results}

Age-dependent expression of AQP2 and AQP3 in response to PUUO

Data on body weight, electrolytes and kidney function are given in Table 1. AQP2 is expressed in the apical plasma membrane and subapical vesicles of collecting duct principal cells. As previously shown, the affinitypurified anti-AQP2 antibody exclusively recognizes the 29 -and the 35 - to $50-\mathrm{kDa}$ bands (Figs. $1 \mathrm{a}, \mathrm{c}$ ). Semiquantitative immunoblotting revealed increased AQP2 abundance in the obstructed and non-obstructed kidneys in PUUO $7 \mathrm{~W}$ (143\% and $125 \%$ of sham levels respectively, $P<0.05$; Fig. 1a, b; Table 2). These findings were confirmed by immunohistochemistry. As described previously, AQP2 labeling was seen in the apical domains of

Table 1 Changes in body weight, plasma electrolytes, and kidney functions in partial unilateral ureteral obstruction (PUUO) and sham-operated control rats at 7 and 14 weeks respectively

\begin{tabular}{|c|c|c|c|c|}
\hline & PUUO-7W $(n=13)$ & Sham-7W $(n=8)$ & PUUO-14W $(n=6)$ & Sham-14W $(n=6)$ \\
\hline Body weight, $g$ & $184 \pm 7.8$ & $187 \pm 10.4$ & $361 \pm 8.2$ & $376 \pm 14.7$ \\
\hline $\mathrm{P}_{\mathrm{osm}}, \mathrm{mosmol} / \mathrm{kgH}_{2} \mathrm{O}$ & $303 \pm 1.3$ & $303 \pm 1.2$ & $302 \pm 1.3$ & $302 \pm 2.4$ \\
\hline Plasma $_{\mathrm{Na}}, \mathrm{mM}$ & $139 \pm 0.5$ & $138 \pm 1.0$ & $142 \pm 0.8$ & $142 \pm 1.2$ \\
\hline Plasma $_{\mathrm{K}}, \mathrm{mM}$ & $3.8 \pm 0.1$ & $3.8 \pm 0.1$ & $3.9 \pm 0.1$ & $3.9 \pm 0.1$ \\
\hline Plasma creatinine, $\mu \mathrm{M}$ & $6.8 \pm 0.7$ & $6.1 \pm 0.5$ & $29 \pm 2.8$ & $25 \pm 1.1$ \\
\hline Plasma urea $\mathrm{mM}$ & $6.4 \pm 0.3$ & $5.9 \pm 0.3$ & $6.6 \pm 0.6^{*}$ & $4.4 \pm 0.5$ \\
\hline $\mathrm{U}_{\mathrm{Vol},}, \mu \mathrm{l} \cdot \mathrm{min}^{-1} \cdot \mathrm{kg}^{-1}$ & $72 \pm 7$ & $73 \pm 11$ & $32.8 \pm 2.5$ & $31.4 \pm 3.1$ \\
\hline $\mathrm{U}_{\mathrm{osm}}, \mathrm{mosmol} / \mathrm{kgH}_{2} \mathrm{O}$ & $1,252 \pm 99$ & $1,245 \pm 98$ & $1,825 \pm 158$ & $1,526 \pm 231$ \\
\hline $\mathrm{U}_{\mathrm{Na}}, \mathrm{mM}$ & $91 \pm 6.6$ & $92 \pm 5.2$ & $121 \pm 10$ & $110 \pm 19$ \\
\hline $\mathrm{U}_{\mathrm{Na}} * \mathrm{~V}, \mu \mathrm{mol} \cdot \mathrm{min}^{-1} \cdot \mathrm{kg}^{-1}$ & $5.86 \pm 0.27$ & $6.15 \pm 0.45$ & $3.90 \pm 0.33$ & $2.88 \pm 0.53$ \\
\hline $\mathrm{FE}_{\mathrm{Na}}, \%$ & $0.19 \pm 0.02$ & $0.17 \pm 0.02$ & $0.50 \pm 0.08$ & $0.43 \pm 0.03$ \\
\hline $\mathrm{FL}_{\mathrm{Na}}, \mu \mathrm{mol} \cdot \mathrm{min}^{-1} \cdot \mathrm{kg}^{-1}$ & $750 \pm 309$ & $833 \pm 55$ & $583 \pm 789$ & $591 \pm 139$ \\
\hline Net $_{\text {Reab. of } \mathrm{Na},} \mu \mathrm{mol} \cdot \mathrm{min}^{-1} \cdot \mathrm{kg}^{-1}$ & $744 \pm 31$ & $827 \pm 54$ & $579 \pm 79$ & $389 \pm 139$ \\
\hline $\mathrm{T}^{\mathrm{C}} \mathrm{H}_{2} \mathrm{O}, \mu \mathrm{l} \cdot \mathrm{min}^{-1} \cdot \mathrm{kg}^{-1}$ & $189 \pm 8.2$ & $193 \pm 5.9$ & $160 \pm 8.1$ & $140 \pm 19$ \\
\hline $\mathrm{Cl}_{\mathrm{Cr},} \mathrm{ml} \cdot \mathrm{min}^{-1} \cdot \mathrm{kg}^{-1}$ & $24.6 \pm 2.6$ & $26.2 \pm 2.2$ & $6.1 \pm 0.9$ & $4.9 \pm 0.9$ \\
\hline
\end{tabular}

Values are means \pm SE. $n=$ number of rats; PUUO-7W, 7-week-old rats subjected to congenital partial unilateral ureteral obstruction; Sham-7W, 7week-old rats subjected to sham operation; PUUO-14W, 14-week-old rats subjected to congenital partial unilateral ureteral obstruction; Sham$14 \mathrm{~W}, 14$-week-old rats subjected to sham operation; $\mathrm{P}_{\mathrm{osm}}$, plasma osmolality; $\mathrm{U}_{\mathrm{Vol}}$, urine output; $\mathrm{U}_{\mathrm{Osm}}$, urine osmolality; $\mathrm{U}_{\mathrm{Na}}$, urine sodium; $\mathrm{U}_{\mathrm{Na}}$

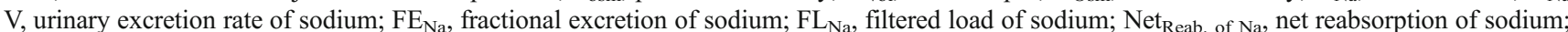
$\mathrm{T}^{\mathrm{C}} \mathrm{H}_{2} \mathrm{O}$, solute-free water reabsorption; $\mathrm{Cl}_{\mathrm{Cr}}$, creatinine clearance; * $P<0.05$ compared with sham 
a

PUUO-7W, pS256-AQP2

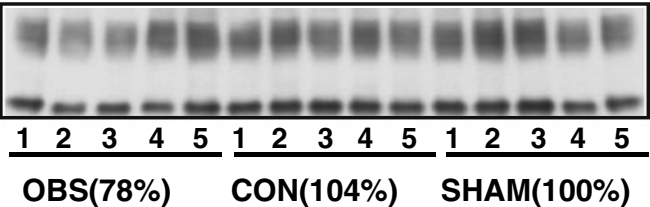

C

PUUO-14W, pS256-AQP2

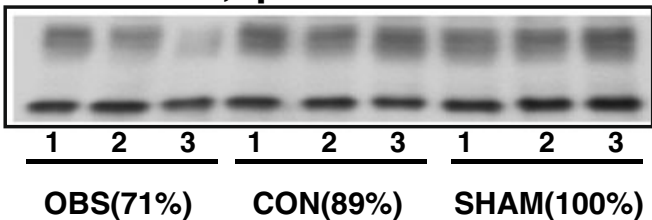

b
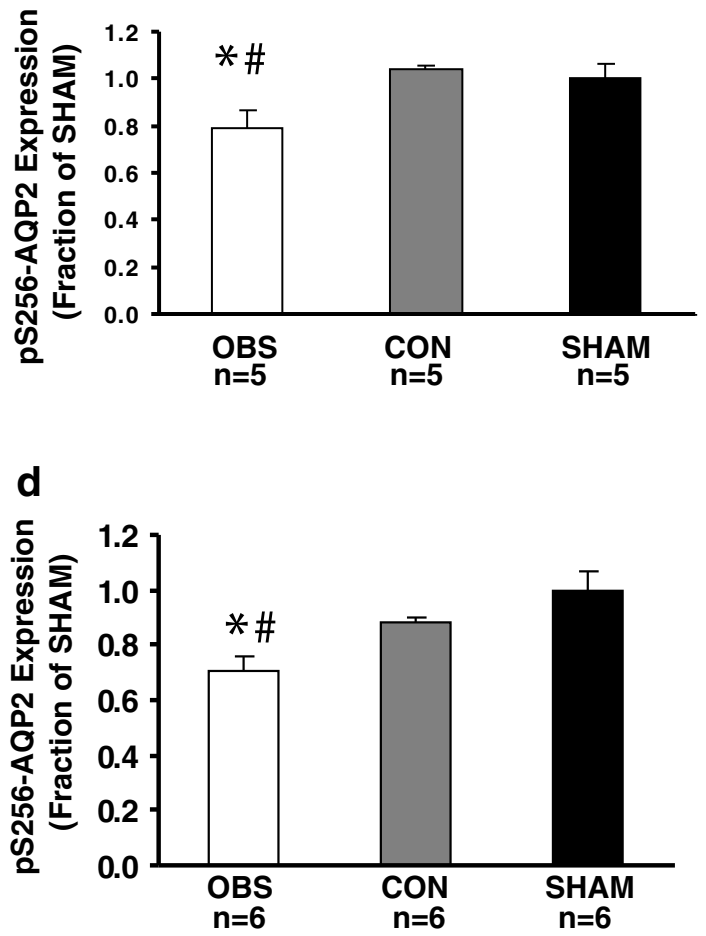
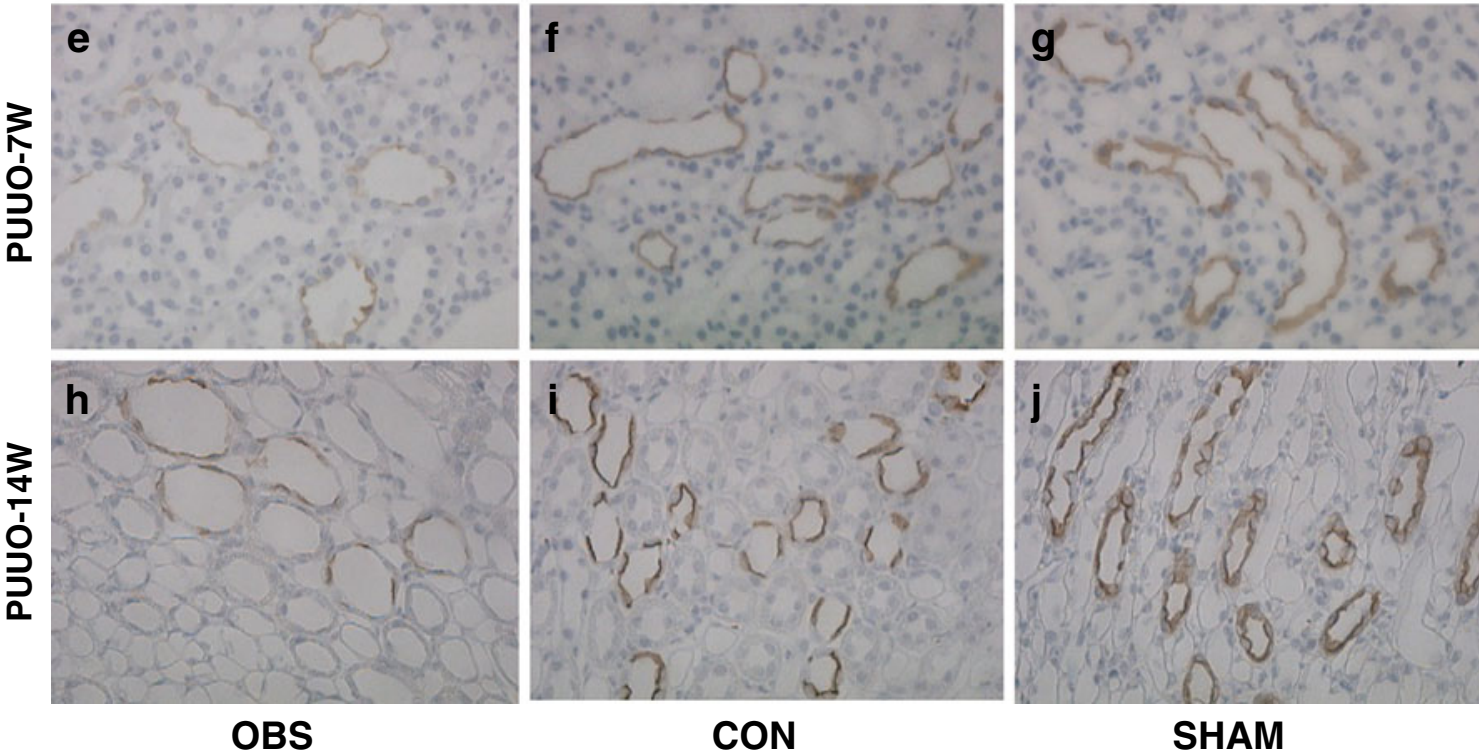

CON

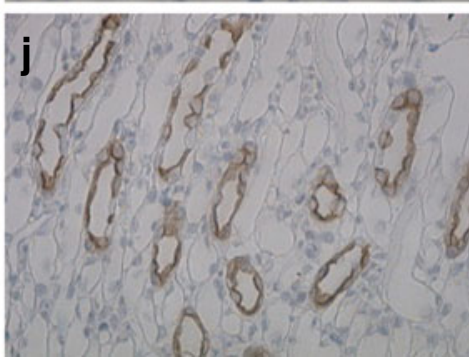

SHAM
Fig. 2 Semiquantitative immunoblotting of membrane fractions of obstructed whole kidneys $(O B S)$ and contralateral non-obstructed kidneys $(C O N)$ from PUUO-7W and PUUO-14W rats, and kidneys from matched sham-operated control rats $(S H A M)$. a and c Immunoblots reacted with affinity-purified phosphorylated AQP2 (pS256AQP2) antibody revealed 29-and 35-to 50-kDa bands. b Densitometry analysis in PUUO-7W revealed a marked decrease in abundance of p-AQP2 to $78 \pm 6 \%$ in OBS. d Densitometry analysis in PUUO$14 \mathrm{~W}$ revealed a marked decrease in expression levels of pS256-AQP2 to $71 \pm 6 \%$ in OBS $\left({ }^{*} P<0.05\right.$ compared with SHAM, ${ }^{*} P<0.05$ compared with $\mathrm{CON}$ ). In CON, p-AQP2 expression did not change in either PUUO-7W or $-14 \mathrm{~W}$. Immunohistochemistry of pS256-AQP2 in the principal cells of collecting duct $(C D)$ of OBS, CON, and SHAM from 7- and 14-week-old PUUO and Sham rats. In the apical parts of the collecting duct principal cells of CD, pS256-AQP2 labeling was much weaker in OBS in both e PUUO-7W and $\mathbf{h}-14 \mathrm{~W}$ rats compared with $\mathbf{g}$, $\mathbf{j}$ SHAM. The immunolabeling in $\mathbf{f}, \mathbf{i}$ CON was comparable to that seen in SHAM. Magnification: $\times 250$ 
the collecting duct principal cells (Fig. 1). In contrast to that seen in the sham-operated controls (Fig. 1g), the labeling intensity of AQP2 in the obstructed kidney (Fig. 1e) and contralateral non-obstructed kidney (Fig. 1f) were increased. In PUUO-14W, AQP2 abundance was significantly decreased in the obstructed kidney $(80 \%$ of sham level, $P<0.05)$, whereas it was unchanged in the non-obstructed kidneys (Fig. 1c, d; Table 1), which were also confirmed by immunohistochemistry (Fig. 1h, i, j).

Semiquantitative immunoblotting of pS256-AQP2 was performed using antibodies that selectively recognize pS256AQP2, which is phosphorylated at consensus site $\left(\operatorname{Ser}^{256}\right)$ [23]. As seen in Fig. 2, pS256-AQP2 protein abundance was reduced in the obstructed kidneys both at 7 weeks (PUUO$7 \mathrm{~W}$ ) and 14 weeks (PUUO-14W; 78\% and $71 \%$ of sham levels respectively, $P<0.05$; Fig. 2 b, d; Table 2), whereas pS256-AQP2 levels were unaltered in non-obstructed kidneys. These findings were confirmed by immunohistochemistry demonstrating that pS256-AQP2 labeling was seen in the apical domains of collecting duct principal cells. In obstructed kidneys, pS256-AQP2 labeling intensity was much weaker in the apical domains of collecting duct principle cells of both PUUO 7W (Fig. 2e) and PUUO 14W (Fig. 2h), compared with sham-operated controls (Fig. 2g, j). In contrast, in nonobstructed kidneys, the labeling intensity of pS256-AQP2 was unchanged (Fig. 2f, i).

AQP3 is the water channel protein expressed in the basolateral plasma membrane of the collecting duct principal cells and plays an important role in collecting duct water reabsorption. Semiquantitative immunoblotting demonstrated increased AQP3 abundance in both obstructed and contralateral non-obstructed kidneys of PUUO-7W (156\% and $152 \%$ of sham level respectively, $P<0.05$, Fig. 3a, b; Table 2). Consistent with this, immunohistochemistry demonstrated an intense labeling intensity of AQP3 in the basolateral plasma membrane domains of the principal cells in the collecting ducts of the obstructed (Fig. 3e) and non-obstructed kidneys (Fig. 3f) compared with sham operated kidney (Fig. 3g). In contrast, in PUUO-14W AQP3 protein abundance did not differ from sham levels (Fig. 3c, d; Table 2). Consistent with this, immunohistochemistry showed the comparable labeling intensity of AQP3 in obstructed and non-obstructed kidneys of PUUO-14W rats (Fig. 3h, i) compared with shamoperated controls (Fig. 3j).

Analysis of kidney weight and total protein content demonstrated that total protein content in the kidneys did not differ significantly among obstructed, non-obstructed, and sham kidneys in PUUO-7W rats, but decreased in the obstructed kidney of PUUO-14W (Table 3).
Table 2 Protein expression of renal AQPs in PUUO and shamoperated control rats at 7 and 14 weeks respectively

\begin{tabular}{clll}
\hline & OBS & CON & SHAM \\
\hline 7 weeks & $(n=5)$ & $(n=5)$ & $(n=5)$ \\
AQP1 & $118 \pm 2 \% *$ & $109 \pm 4 \%$ & $100 \pm 5 \%$ \\
AQP2 & $143 \pm 12 \% *$ & $125 \pm 7 \% *$ & $100 \pm 7 \%$ \\
p-AQP2 & $78 \pm 6 \% *$, & $104 \pm 2 \%$ & $100 \pm 6 \%$ \\
AQP3 & $156 \pm 21 \% *$ & $152 \pm 5 \% *$ & $100 \pm 8 \%$ \\
14 weeks & $(n=6)$ & $(n=6)$ & $(n=6)$ \\
AQP1 & $76 \pm 8 \% *$ & $83 \pm 6 \% *$ & $100 \pm 3 \%$ \\
AQP2 & $80 \pm 8 \% *$ & $88 \pm 5 \%$ & $100 \pm 3 \%$ \\
p-AQP2 & $71 \pm 6 \% *$, & $89 \pm 1 \%$ & $100 \pm 6 \%$ \\
AQP3 & $85 \pm 7 \%$ & $101 \pm 4 \%$ & $100 \pm 9 \%$ \\
\hline
\end{tabular}

Values are means $\pm \mathrm{SE}$; $n$,number of rats; PUUO, partial unilateral ureteral obstruction; OBS, obstructed kidney; $\mathrm{CON}$, contralateral nonobstructed kidney; SHAM, sham-operated kidney

$* P<0.05$ compared with SHAM; $\propto P<0.05$ compared with CON

Age-dependent expression of AQP1 in response to PUUO

AQP1 is a water channel protein expressed in the proximal tubule and the descending thin limb of Henle's loop. Semiquantitative immunoblotting revealed that AQP1 abundance was increased in the obstructed kidneys in PUUO-7W rats compared with sham-operated controls (118\% of sham levels, $P<0.05$, Fig. $4 \mathrm{a}$, b; Table 2 ). These findings were also observed by immunohistochemistry (Fig. 4e, f, g). In PUUO-14W, AQP1 abundance was significantly decreased in the obstructed and non-obstructed kidney $(76 \%$ and $83 \%$ of sham level respectively, $P<0.05$; Fig. 4c, d; Table 2), which was also seen by the immunohistochemistry (Fig. 4h, i, j).

\section{Discussion}

The present study demonstrated that protein abundance of renal AQP2 and AQP3 was increased in both partial obstructed and non-obstructed kidneys 7 weeks after induction of neonatal PUUO. AQP1 protein abundance was increased in the obstructed kidney of PUUO-7W rats. In contrast, AQP1 and AQP2 protein abundance were reduced in obstructed kidneys 14 weeks after induction of PUUO. pS256-AQP2 protein abundance was reduced at both 7 and 14 weeks after PUUO, and confirmed by immunohistochemistry demonstrating that trafficking of $\mathrm{AQP} 2$ to the apical plasma membrane is impaired despite age-dependent changes in total AQP2 abundance. 
a

PUU0-7W, AQP3

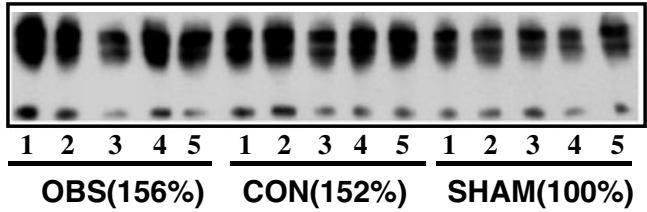

C

PUU0-14W, AQP3

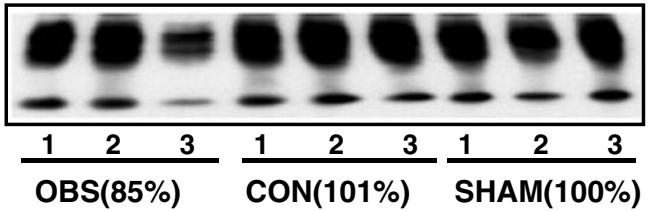

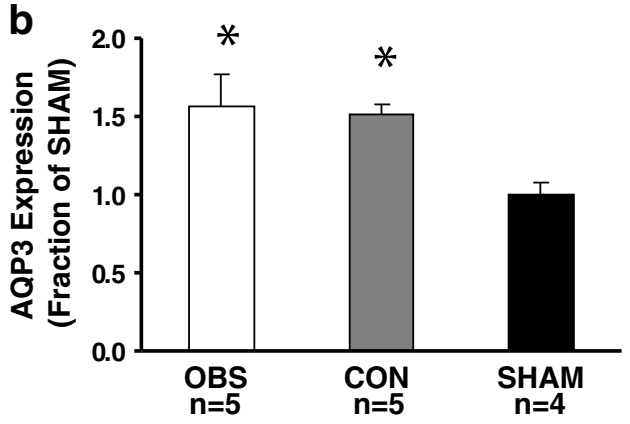

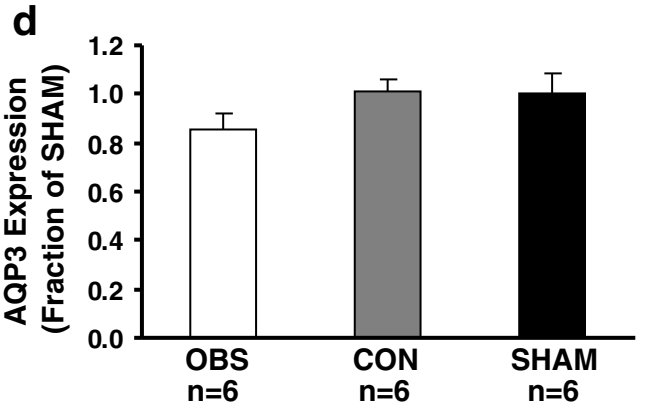

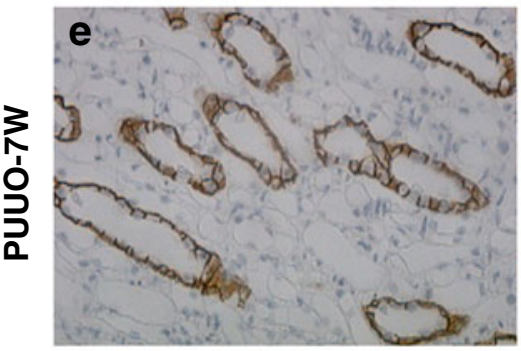

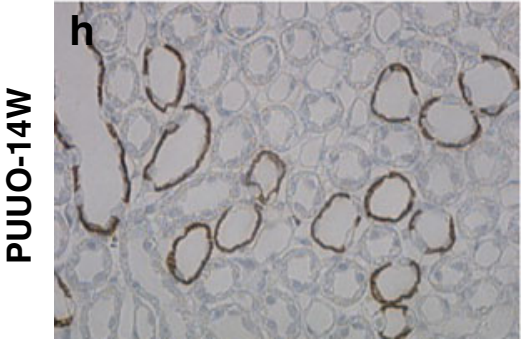

OBS
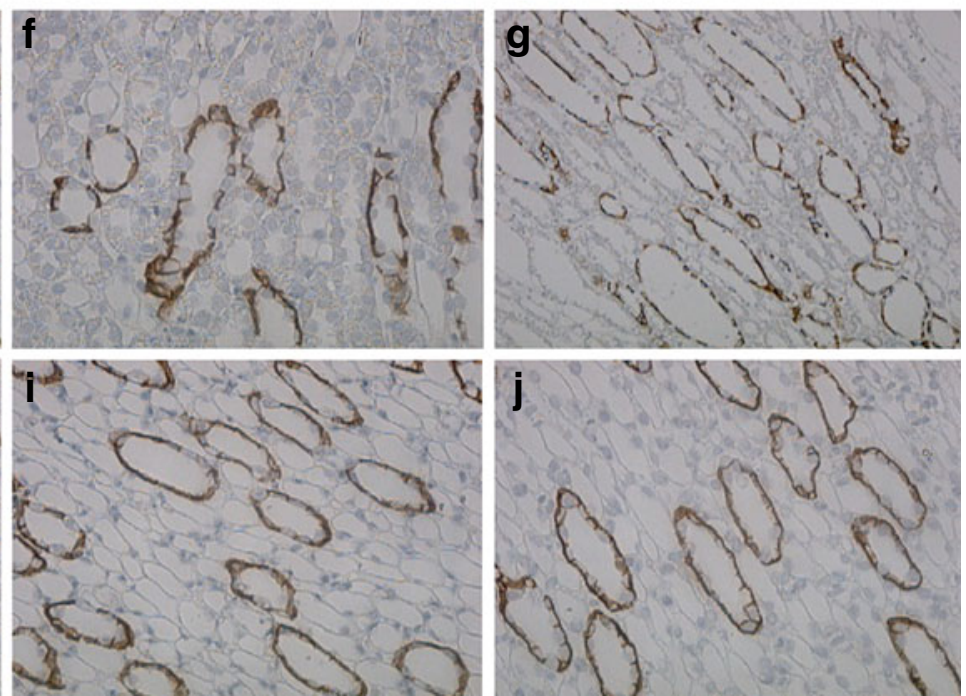

CON

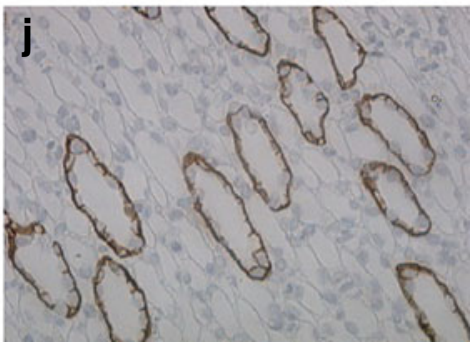

SHAM
Fig. 3 Semiquantitative immunoblotting of membrane fractions of obstructed whole kidneys $(O B S)$ and contralateral non-obstructed kidneys $(C O N)$ from PUUO-7W and PUUO-14W rats, and kidneys from matched sham-operated rats $(S H A M)$. a, c Immunoblots reacted with affinity-purified AQP3 antibody and revealed 27-and 33-to 40kDa bands. b Densitometry analysis in PUUO-7W revealed a marked increase in abundance of AQP3 to $156 \pm 21 \%$ in OBS and $152 \pm 5 \%$ in
CON ( $P<0.05$ separately, compared with SHAM). d Densitometry analysis in PUUO-14W revealed an unchanged abundance of AQP3. In PUUO-7W rats, the immunolabeling of AQP3 in the collecting duct was intense in e OBS and $\mathbf{f}$ CON compared with $\mathbf{g}$ SHAM, whereas in PUUO-14W the immunolabeling was comparable in $\mathbf{h}$ OBS and $\mathbf{i}$ CON compared with j SHAM. Magnification: $\times 250$

ing with reduced free water reabsorption. Thus, these studies have demonstrated a functional association between protein abundance and ability to move water across the tubular epithelium, suggesting a key pathophysiological role of renal water channels for the impaired urine concentrating capacity that may be associated with urinary 
Table 3 Kidney weight and protein concentration in PUUO and sham-operated control rats at 7 and 14 weeks respectively

Values are means $\pm \mathrm{SE} ; n$, number of rats; OBS:,obstructed kidney; CON, contralateral non-obstructed kidney; SHAM, sham operated kidney

$* P<0.05$ compared with CON

\begin{tabular}{lccc}
\hline & OBS & CON & SHAM \\
\hline 7 weeks & $(n=5)$ & $(n=5)$ & $(n=5)$ \\
Kidney weight $(\mathrm{g})$ & $1.17 \pm 0.11$ & $1.00 \pm 0.06$ & $0.89 \pm 0.06$ \\
Protein concentration $(\mu \mathrm{g} / \mu \mathrm{l})$ & $9.61 \pm 1.12$ & $9.96 \pm 1.23$ & $9.16 \pm 0.64$ \\
14 weeks & $(n=6)$ & $(n=6)$ & $(n=6)$ \\
Kidney weight $(\mathrm{g})$ & $0.94 \pm 0.11^{*}$ & $1.27 \pm 0.06$ & $1.17 \pm 0.07$ \\
Protein concentration $(\mu \mathrm{g} / \mu \mathrm{l})$ & $11.5 \pm 1.4^{*}$ & $15.3 \pm 0.9$ & $14.3 \pm 0.6$ \\
\hline
\end{tabular}

regulation is associated with impaired urinary concentrating capacity after obstruction [25]. Since the regulation of the four different aquaporin water channels is dependent on the duration of obstruction in the present model of congenital partial unilateral ureter obstruction, it will be important to examine the urine concentrating capacity of the partially obstructed kidney in a future study.

AQP3 represents an exit pathway for water transport through the basolateral membrane in collecting duct principal cells and also plays a role in the urine concentration. It is well known that AQP3 knockout mice have a marked polyuria and impairment of urinary concentration [26]. Immunoblotting and immuohistochemistry demonstrated that AQP3 was markedly upregulated in both obstructed and contralateral non-obstructed kidneys in PUUO-7W rats compared with the sham animals. In contrast, the observed unchanged expression of AQP3 in PUUO-14W rats suggests that regulation of AQP3 abundance was different from that of AQP2. Vasopressin is known to increase the abundance of both AQP2 and AQP3 in the collecting duct, and there is clear evidence that regulation of both $\mathrm{AQP} 2$ and $\mathrm{AQP} 3$ abundance is related to changes of body water balance [27]. However, immunoelectron microscopy previously demonstrated that AQP3 is exclusively present in the basolateral plasma membranes with little labeling of intracellular vesicles [12]. This suggests that $\mathrm{AQP} 3$ is not regulated by vesicular trafficking. Moreover, there are several examples where there is a decoupling of AQP2 and AQP3 expression, e.g., in conditions like hepatic cirrhosis [28], vasopressin escape [29], and low-protein diet [30]. This finding suggests that other factors in addition to vasopressin may regulate AQP3 abundance. We also previously demonstrated that AQP3 abundance and expression in the basolateral plasma membrane of the collecting duct principal cells are, at least in part, dependent on the plasma aldosterone levels [24], and the increase in AQP3 protein abundance in the contralateral non-obstructed kidney may be an adaptive phenomenon.

Age-dependent expression of AQP1

AQP1 is expressed in the proximal tubule and descending thin limb of Henle. AQP1 plays a vital role in water obstruction [14] and it was shown that AQP2 down- 
a

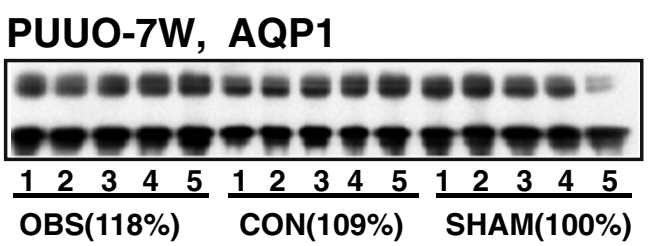

C

PUU0-14W, AQP1

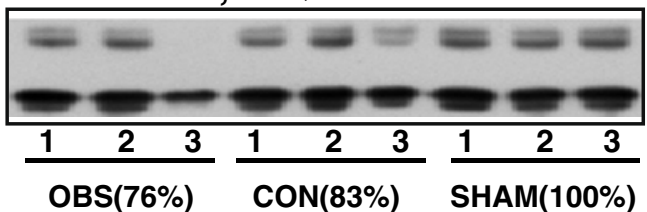

b

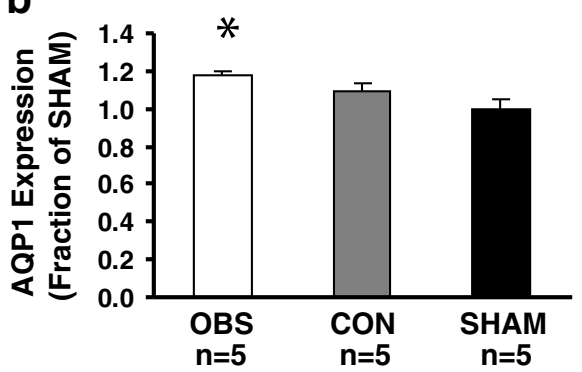

d

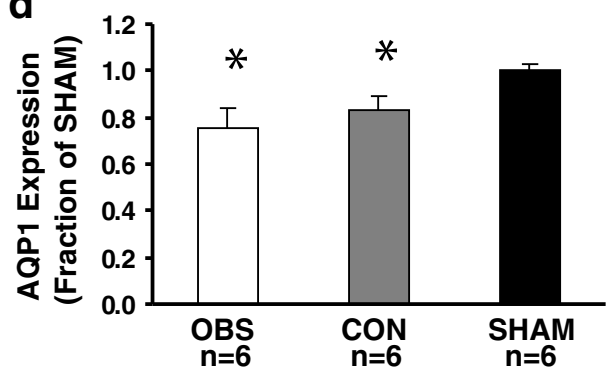

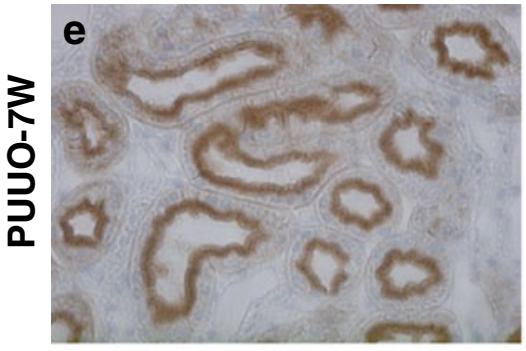
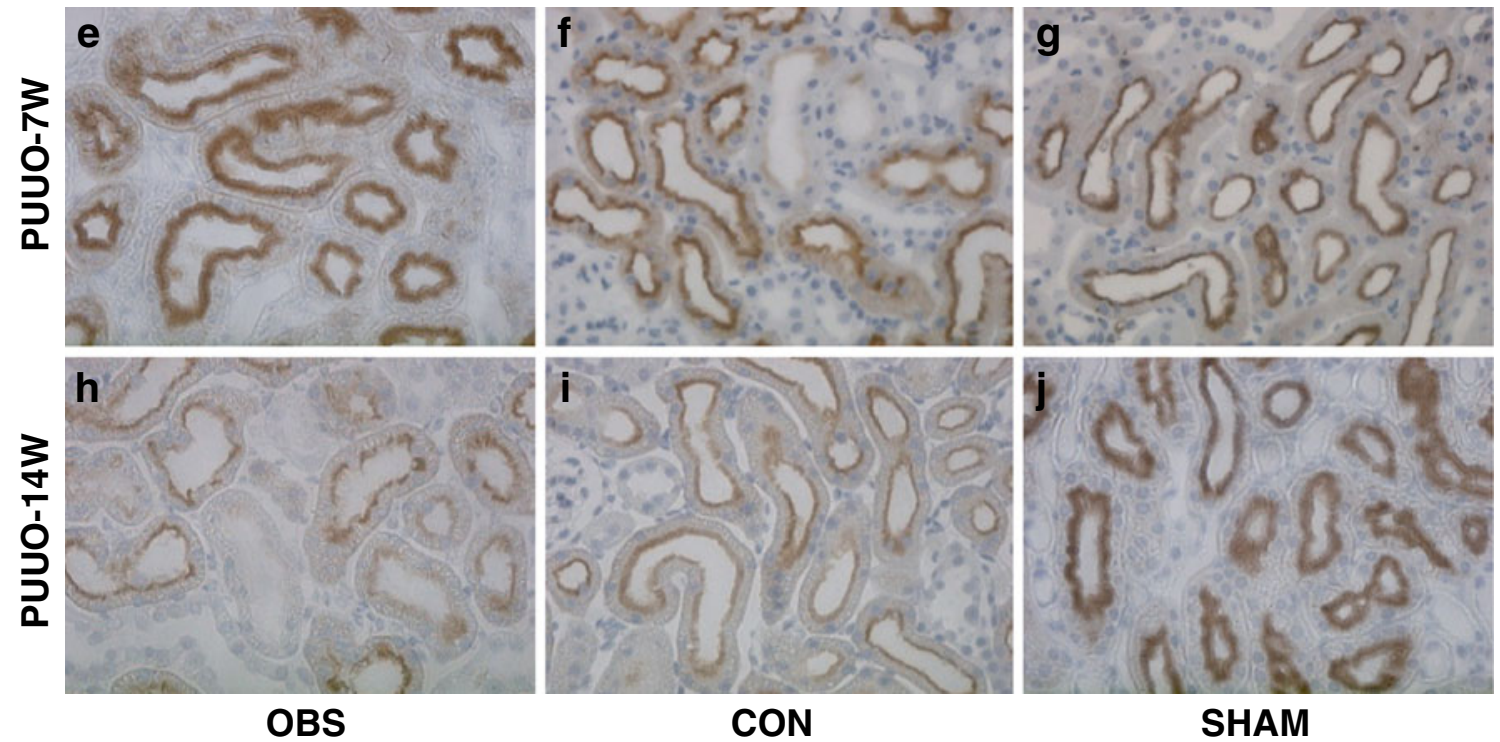

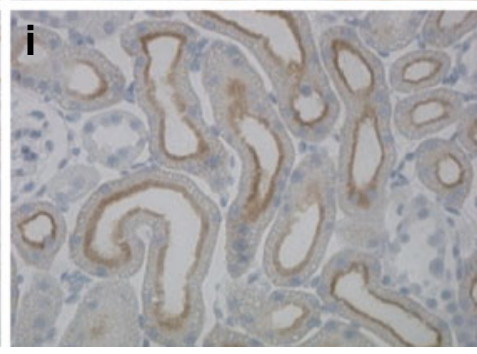

CON

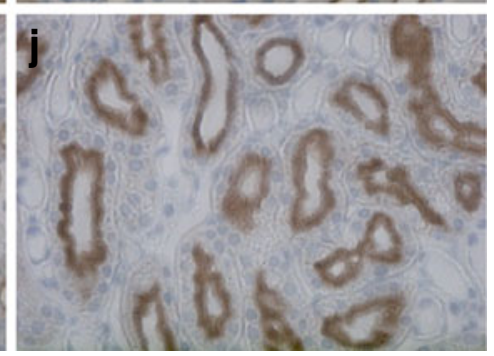

SHAM
Fig. 4 Semiquantitative immunoblotting of membrane fractions of obstructed whole kidneys $(O B S)$ and contralateral non-obstructed kidneys $(C O N)$ from PUUO-7W and PUUO-14W rats, and kidneys from matched sham-operated control rats $(S H A M)$. a, c Immunoblots reacted with affinity-purified AQP1 antibody revealed 29-and 35-to $50-\mathrm{kDa}$ bands. b Densitometry analysis in PUUO-7W revealed increased abundance of AQP1 to $118 \pm 2 \%$ in OBS $(P<0.05)$. In CON, AQP1 expression did not change. d Densitometry analysis in

reabsorption by catalyzing coupling between $\mathrm{NaCl}$ and water movement in isosmotic fluid transport and allowing osmotic equilibrium in the presence of tubular rapid flow. Consistent with this, AQP1 knockout mice have a severe urinary concentration defect and decreased transepithelial water permeability in the proximal tubule and descending thin limb [31, 32]. Moreover, dysregulation of AQP1 may result in changes in tubular fluid delivery to the thick
PUUO-14W revealed a markedly decreased abundance of AQP1 to 76 $\pm 8 \%$ in OBS and $83 \pm 6 \%$ in CON $(P<0.05$ separately, compared with SHAM). Immunohistochemistry of AQP1 in the proximal tubule of OBS, CON, and SHAM kidneys from 7- and 14-week-old PUUO and Sham rats. In PUUO-7W rats the immunolabeling was intense in $\mathbf{e}$ OBS, and comparable in $\mathbf{f}$ CON compared with $\mathbf{g}$ SHAM. In PUUO$14 \mathrm{~W}$ the immunolabeling was much weaker in $\mathbf{h}$ OBS and $\mathbf{i}$ CON compared with j SHAM. Magnification: $\times 250$

ascending limb and collecting duct, and thereby also partly contribute to the impaired urinary concentration ability after urinary tract obstruction. Recently, we demonstrated that AQP1 expression is reduced in response to both bilateral ureteral obstruction and unilateral ureteral obstruction [14, 15]. Consistent with this, the results of the present study showed decreased AQP1 abundance in obstructed kidneys from PUUO-14W. Similar to the collecting duct aquapor- 
ins, AQP1 abundance was increased in the obstructed kidney of PUUO-7W rats. Overall, the results of the present study extend previous findings and underscore the importance of AQP1 dysregulation in response to obstruction. The early upregulation may be a compensatory phenomenon, whereas the late downregulation may suggest that downregulation of this protein is also dependent on age and duration of a congenital partial obstruction. The downregulation of AQP1 observed in the contralateral kidney of PUUO-14W rats may suggest a physiological adaptive response by the opposite kidney.

In conclusion, the study demonstrated an increase in $\mathrm{AQP} 2, \mathrm{AQP} 3$, and $\mathrm{AQP} 1$ protein abundance in the obstructed kidney in PUUO-7W rats coinciding with reduced pS256$\mathrm{AQP} 2$ protein abundance. This increase in $\mathrm{AQP} 2, \mathrm{AQP} 3$, and AQP1 protein abundance may be an early compensatory phenomenon of the obstructed kidney to prevent obstructioninduced impairment of membrane transport functions along the nephron. Consistent with previous studies AQP2, pS256$\mathrm{AQP} 2, \mathrm{AQP} 3$, and $\mathrm{AQP1}$ protein abundance were reduced in the obstructed kidney in PUUO-14W rats suggesting that this may contribute to the impairment of urinary concentration in kidneys with congenital urinary tract obstruction.

Acknowledgements The authors thank Gitte Kall, Gitte Skou, Inger Merete Paulsen, and Line V. Nielsen for expert technical assistance. The Water and Salt Research Centre at the University of Aarhus is established and supported by the Danish National Research Foundation (Danmarks Grundforskningsfond). Support for this study was provided by The Karen Elise Jensen Foundation, The Commission of the European Union (QRLT-2000-00987 and QLRT-2000-00778), The Human Frontier Science Program, The WIRED program (Nordic Council and the Nordic Centre of Excellence Program in Molecular Medicine), The Novo Nordisk Foundation, and Aarhus University. The Danish Medical Research Council and The National Research Foundation were funded by the Ministry of Education, Science and Technology, Korea (R01-2007-000-20441-0).

Open Access This article is distributed under the terms of the Creative Commons Attribution Noncommercial License which permits any noncommercial use, distribution, and reproduction in any medium, provided the original author(s) and source are credited.

\section{References}

1. Klahr S (2001) Urinary tract obstruction. In: Schrier RW (ed) Disease of the kidney and urinary tract, vol 1, 7th edn. Lippincott Williams \& Wilkins, Philadelphia, pp 757-787

2. Koff SA, Campbell KD (1994) The nonoperative management of unilateral neonatal hydronephrosis: natural history of poorly functioning kidneys. J Urol 152:593-595

3. Peters CA (1997) Obstruction of the fetal urinary tract. J Am Soc Nephrol 8:653-663

4. Wen JG, Chen Y, Frokiaer J, Jorgensen TM, Djurhuus JC (1998) Experimental partial unilateral ureter obstruction. I. Pressure flow relationship in a rat model with mild and severe acute ureter obstruction. J Urol 160:1567-1571
5. Chevalier RL, Thornhill BA, Wolstenholme JT, Kim A (1999) Unilateral ureteral obstruction in early development alters renal growth: dependence on the duration of obstruction. J Urol 161:309-313

6. Glassberg KI (2001) The valve bladder syndrome: 20 years later. J Urol 166:1406-1414

7. Knepper MA (1997) Molecular physiology of urinary concentrating mechanism: regulation of aquaporin water channels by vasopressin. Am J Physiol 272:F3-F12

8. Nielsen S, Kwon TH, Christensen BM, Promeneur D, Frokiaer J, Marples D (1999) Physiology and pathophysiology of renal aquaporins. J Am Soc Nephrol 10:647-663

9. Nielsen S, Pallone T, Smith BL, Christensen EI, Agre P, Maunsbach AB (1995) Aquaporin-1 water channels in short and long loop descending thin limbs and in descending vasa recta in rat kidney. Am J Physiol 268:F1023-F1037

10. Nielsen S, DiGiovanni SR, Christensen EI, Knepper MA, Harris HW (1993) Cellular and subcellular immunolocalization of vasopressin-regulated water channel in rat kidney. Proc Natl Acad Sci USA 90:11663-11667

11. Nielsen S, Chou CL, Marples D, Christensen EI, Kishore BK, Knepper MA (1995) Vasopressin increases water permeability of kidney collecting duct by inducing translocation of aquaporin-CD water channels to plasma membrane. Proc Natl Acad Sci USA 92:1013-1017

12. Ecelbarger CA, Terris J, Frindt G, Echevarria M, Marples D, Nielsen S, Knepper MA (1995) Aquaporin-3 water channel localization and regulation in rat kidney. Am J Physiol 269: F663-F672

13. Terris J, Ecelbarger CA, Marples D, Knepper MA, Nielsen S (1995) Distribution of aquaporin-4 water channel expression within rat kidney. Am J Physiol 269:F775-F785

14. Frokiaer J, Christensen BM, Marples D, Djurhuus JC, Jensen UB, Knepper MA, Nielsen S (1997) Downregulation of aquaporin-2 parallels changes in renal water excretion in unilateral ureteral obstruction. Am J Physiol 273:F213-F223

15. Li C, Wang W, Knepper MA, Nielsen S, Frokiaer J (2003) Downregulation of renal aquaporins in response to unilateral ureteral obstruction. Am J Physiol Renal Physiol 284:F1066-F1079

16. Shi Y, Li C, Thomsen K, Jorgensen TM, Knepper MA, Nielsen S, Djurhuus JC, Frokiaer J (2004) Neonatal ureteral obstruction alters expression of renal sodium transporters and aquaporin water channels. Kidney Int 66:203-215

17. Wang G, Topcu SO, Ring T, Wen J, Djurhuus JC, Kwon TH, Nielsen S, Frokiaer J (2009) Age-dependent renal expression of acid-base transporters in neonatal ureter obstruction. Pediatr Nephrol 24:1487-1500

18. Shi Y, Pedersen M, Li C, Wen JG, Thomsen K, Stodkilde-Jorgensen H, Jorgensen TM, Knepper MA, Nielsen S, Djurhuus JC, Frokiaer J (2004) Early release of neonatal ureteral obstruction preserves renal function. Am J Physiol Renal Physiol 286:F1087-F1099

19. Ulm AH, Miller F (1962) An operation to produce experimental reversible hydronephrosis in dogs. J Urol 88:337-341

20. Phifer CB, Terry LM (1986) Use of hypothermia for general anesthesia in preweanling rodents. Physiol Behav 38:887890

21. O’Neill H, Lebeck J, Collins PB, Kwon TH, Frokiaer J, Nielsen S (2008) Aldosterone-mediated apical targeting of ENaC subunits is blunted in rats with streptozotocin-induced diabetes mellitus. Nephrol Dial Transplant 23:1546-1555

22. Nielsen J, Kwon TH, Praetorius J, Frokiaer J, Knepper MA, Nielsen S (2006) Aldosterone increases urine production and decreases apical AQP2 expression in rats with diabetes insipidus. Am J Physiol Renal Physiol 290:F438-F449

23. Christensen BM, Zelenina M, Aperia A, Nielsen S (2000) Localization and regulation of PKA-phosphorylated AQP2 in 
response to $\mathrm{V}(2)$-receptor agonist/antagonist treatment. Am J Physiol Renal Physiol 278:F29-F42

24. Kwon TH, Nielsen J, Masilamani S, Hager H, Knepper MA, Frokiaer J, Nielsen S (2002) Regulation of collecting duct AQP3 expression: response to mineralocorticoid. Am J Physiol Renal Physiol 283:F1403-F1421

25. Frøkiær J, Marples D, Knepper MA, Nielsen S (1996) Bilateral ureteral obstruction downregulates expression of vasopressinsensitive AQP-2 water channel in rat kidney. Am J Physiol Renal Physiol 270:F657-F668

26. Ma T, Song Y, Yang B, Gillespie A, Carlson EJ, Epstein CJ, Verkman AS (2000) Nephrogenic diabetes insipidus in mice lacking aquaporin-3 water channels. Proc Natl Acad Sci USA 97:4386-4391

27. Terris J, Ecelbarger CA, Nielsen S, Knepper MA (1996) Longterm regulation of four renal aquaporins in rats. Am J Physiol 271: F414-F422
28. Fernandez-Llama P, Turner R, Dibona G, Knepper MA (1999) Renal expression of aquaporins in liver cirrhosis induced by chronic common bile duct ligation in rats. J Am Soc Nephrol 10:1950-1957

29. Ecelbarger CA, Murase T, Tian Y, Nielsen S, Knepper MA, Verbalis JG (2002) Regulation of renal salt and water transporters during vasopressin escape. Prog Brain Res 139:75-84

30. Sands JM, Naruse M, Jacobs JD, Wilcox JN, Klein JD (1996) Changes in aquaporin-2 protein contribute to the urine concentrating defect in rats fed a low-protein diet. J Clin Invest 97:2807-2814

31. Chou CL, Knepper MA, Hoek AN, Brown D, Yang B, Ma T, Verkman AS (1999) Reduced water permeability and altered ultrastructure in thin descending limb of Henle in aquaporin-1 null mice. J Clin Invest 103:491-496

32. Schnermann J, Chou CL, Ma T, Traynor T, Knepper MA, Verkman AS (1998) Defective proximal tubular fluid reabsorption in transgenic aquaporin-1 null mice. Proc Natl Acad Sci USA 95:9660-9664 